\title{
Erratum to: Optical coherence tomographic parameters as objective signs for visual acuity in patients with retinitis pigmentosa, future candidates for retinal prostheses
}

Miho Tamaki - Toshihiko Matsuo

Published online: 22 September 2011

(C) The Japanese Society for Artificial Organs 2011

Erratum to: J Artif Organs (2011) 14:140-150

DOI 10.1007/s10047-011-0557-9

The terms "hand movement," "light perception," and "no light perception" throughout the text and legends for figures should read "counting fingers," "hand movement," and "light perception," respectively.

These changes do not affect the results and conclusions in the article.

The online version of the original article can be found under doi:10.1007/s10047-011-0557-9.

M. Tamaki · T. Matsuo ( $\)$

Department of Ophthalmology, Okayama University

Medical School and Graduate School of Medicine,

Dentistry, and Pharmaceutical Sciences,

Shikata-cho 2-5-1, Okayama 700-8558, Japan

e-mail: matsuot@cc.okayama-u.ac.jp 